\title{
Motivation and ability: which students use online learning and what influence does it have on their achievement?
}

\author{
Sherria L. Hoskins and Johanna C. van Hooff \\ University of Portsmouth
}

\section{Correspondence should be sent to:}

Dr Sherria Hoskins

Department of Psychology

University of Portsmouth

King Henry Building

King Henry I Street

Portsmouth

PO1 2DY

Email: Sherria.hoskins@port.ac.uk

\section{Notes:}

Dr Sherria Hoskins is a Senior Lecturer in psychology at the University of Portsmouth. Her research focuses on social cognitive aspects of learning and professional development across the lifespan, particularly the relationship between motivation, learning environment and academic success.

Dr Johanna van Hooff is a Senior Lecturer in psychology at the University of Portsmouth. Her research focuses on brain measures of explicit and implicit memory and on the development and evaluation of on-line learning environments. 


\begin{abstract}
There has been much recent research examining online learning in universities, but two questions seem to have been largely overlooked in this context, 1) which students voluntarily utilise Web-based learning and 2) does this use influence their academic achievement? The current study aimed to determine whether the approaches to studying, ability, age, and gender of 110 undergraduates in the $2^{\text {nd }}$ year of a psychology degree predicted the extent to which they utilised online learning using Web Course Tools (WebCT) in support of a core Biological Psychology unit. Data were obtained from WebCT's student tracking system, Entwistle and Ramsden's 18 item Approaches to Studying Inventory (1983) and academic records. Multiple linear regressions, and discriminant function analysis were used to examine whether individual differences predicted WebCT use, while analysis of covariance determined whether Web use influenced academic achievement. The number of hits, length of access and use of the bulletin board was predicted by age, with older students using WebCT more. These factors were also influenced by ability and achievement orientation. The degree of participation in self-assessment was not predicted by student variables, but, of those that repeated an online quiz, improvement was more likely in those with lower achievement orientation. Only bulletin board use influenced achievement, with those posting messages outperforming those not using, or passively using bulletin boards. However, since individual differences will determine the extent to which students utilise this facility it is suggested that future research should focus on developing online learning environments that incorporate activities with both a beneficial influence on learning and appeal to a wide student population.
\end{abstract}


Although it is rare for the World Wide Web (hereafter referred to as the Web) to be used to deliver "virtual lectures . . . virtual libraries and . . . final examinations in virtual assessment halls” (Howe, 1998 p.371) interest in Web-based learning in higher education is increasing, as can be seen by the vast number of recent publications in this area. The increasing interest is not surprising and may be considered inevitable as we shift to a system of mass higher education (Maye, 1998). Web-based learning is certainly an option that offers instructors a range of advantages, such as, providing feedback with relative ease (Collis, De-Boer \& Slotman, 2001), enabling a more flexible pace of learning (Sherman, 1998; Ward \& Newlands, 1998), and reaching and motivating a large and diverse audience (Plous, 2000). It may therefore open access and widen potential markets, while decreasing the resources that are required to maintain courses and to promote student learning. Other research highlights the benefits of Webbased learning for students, suggesting that it affords them greater anonymity (Howe, 1998) and opportunities to practice a range of generic skills (e.g., management of self, others, task, information) (Oliver \& McLoughlin, 2001). In addition, they can profit from an interactive and engaging environment with a range of learning scaffolds and supports (Krantz \& Eagley, 1996), which may enable them to broaden and make sense of their experience (Hammond \& Trapp, 2001). Finally, providing students with the opportunity and reason to interface with computers on a regular basis will likely benefit their computer literacy, which can be considered a 'critical filter' for the employment market of the future (Miura, 1987; Heinssen, Glass \& Knight, 1987).

However, while this form of instruction is understandably gaining acceptance as an alternative to traditional teaching, research on its effectiveness is still in its infancy 
(Arbaugh, 2000) and questions that have been thoroughly studied for traditional teaching methods may need to be revisited with regard to online learning. Hence, as demand for Web-based courses grows, so too does the need for systematic evaluation of these learning environments (Owston, 2000). That is not to say that useful research hasn't already been carried out. Since the late 1990s there has been much research examining Web-based learning, in terms of how best to design Web resources to facilitate learning (e.g. Hammond \& Trapp, 2001), how to evaluate Web-learning (e.g. Owston, 2000), how to measure students perceptions of online learning environments (Jiang \& Ting, 2000), and how this method of delivery affects achievement (e.g. Ross, 2000).

However, much of the research overlooks how individual differences influence students' willingness to embrace learning technology. Gender and age are perhaps the only factors that have been examined to some degree. For example, Chmielewski (1998) found that males have significantly more knowledge of the Web, and use the Web more often than females. Arbaugh (2000) however, found that men $(\mathrm{N}=14)$ relative to women $(\mathrm{N}=13)$ reported more difficulty interacting in an asynchronous internet-based MBA course, which was also a significant predictor of class participation. A larger study carried out by Jackson, Ervin, Gardner and Schmitt (2001) supported the finding that men are less inclined to enter into dialogue via the Web. They examined 630 undergraduates (403 females, 227 males; mean age 20 yrs) who completed the Student Computer and Internet Survey. Internet use was separated into e-mail and Web use to distinguish the communication and information motives served by the Internet. Results showed that females used e-mail more than males (revealing a communication motive), 
and that males used the Web more than females (indicating the motive to gain information without communication).

With respect to age and Internet use, it is older adults that have been given most attention, perhaps due to the stereotypical belief that they are less inclined to use such learning environments. Some research has confirmed this with people over the age of 55, who have been reported to use the Web significantly less than any other age group (Chmielewski, 1998). In a survey of domestic Web use in middle-aged (aged 40-59 yrs), young-old (aged 60-74 yrs), and old-old adults (aged 75-92 yrs) Morrell, Mayhorn and Bennett (2000) confirm that there are distinct age differences in individuals who use the Web with oldest adults showing the least interest in using the Web. However, in an academic environment the age of potential users is likely to be significantly lower and of a smaller range than in this study. Little is known, for example, about how those often categorised as traditional university entrants (up to 21) and non-traditional entrants (over 21) differ in their use of online learning environments.

In much of the existing research, there are two variables that are not examined but that may confound any evaluation of age and gender in relation to Web-based learning: Motivation and ability. Moreover, it has been found that elements of motivation (as examined via measures of approaches to studying, learning styles and orientation) do relate to gender to some degree (Hayes \& Richardson, 1995; Rogers, Galloway, Armstrong \& Leo, 1998) and to age to a greater extent (Harper \& Kember, 1986; Richardson 1994, 1997; Newstead, Hoskins, Franklyn-Stokes \& Dennis, 1997). So too has it been suggested that the way in which information technology (IT) is utilised 
depends largely on students’ motivation (Tolmie \& Anderson, 1989). Martinez (1999) also suggests that with the increasingly rapid changes in technology, learning orientation is an important learner-difference variable. Hence, educators considering the use of IT in education need to also consider the foundational concepts of learning theories, such as those based on constructivism, which emphasise individual differences in learning styles (Musgrove, Knee, Rodney \& Musgrove, 2001). Furthermore, teaching and learning which utilises IT may not be appropriate for all learners (see Enochs, Handley \& Wollenberg, 1985; Wood, Ford, Miller, Sobczyk \& Duffin, 1996; Ross \& Schulz, 1999). However, it must be noted that these investigations were carried out in human computer interaction scenarios rather than to investigate students' voluntary use of Web-based material, aimed at supporting and enhancing existing courses.

With regard to ability, existing research demonstrated that age is a powerful predictor of achievement, with mature students gaining better degrees on average than younger students, while gender is a weak predictor, with a trend for females to perform better than males (Hoskins, Newstead and Dennis, 1997). It is not yet known however, what impact general ability has on the use of Web-based learning. Neither do we know how any of these student variables influence the effectiveness of this method of learning when employed.

From the above it becomes clear that two important questions seem to have been overlooked in the research to date (i) Which students voluntarily utilise Web-based learning? and (ii) How does this use influence their academic achievement? The current 
investigation aimed to answer these questions by examining students’ age, gender, academic ability (grade from the previous academic year) and approaches to studying (meaning orientation, reproducing orientation and achieving orientation, as described by Entwistle and Ramsden, 1983), in relation to their use of a Web-based learning environment. Approaches to studying are measured using Entwistle and Ramsden's (1983) Approaches to Studying Inventory (ASI). Furthermore, use of Web-based resources was examined in relation to subsequent academic achievement, while controlling for these student variables. Individual differences in Web use were determined using the WebCT facility that monitors students' online activity, rather than via self-report which may be flawed. More specifically, general Web use was based on the number of times the Web site was accessed by each student, and the length and timing of access. Use of the Web for dialogue was measured in terms of students' use of the interactive bulletin board. In addition, the extent to which students utilised selfassessment opportunities was examined using data from an on-line quiz that was offered to the students (i.e., number of times this quiz was attempted, the amount of time spent on the quiz and the quiz marks).

\section{Method}

\section{Participants}

Participants were 110 of 143 second-year psychology undergraduates (77\%). The missing 33 students did not fill in, or did not return the ASI (see next section), which was distributed to students in the second semester of the first year. There were 93 females and 17 males. They varied in age between 19 and 43, with a mean age of 20 years. The vast majority of students were younger than 22 years. The 'older' students 
were aged $24(n=1), 27(n=4), 30(n=1), 31(n=1), 35(n=1), 36(n=1)$, and $43(n=1)$. These distributions accurately represent the demographics of the whole cohort of 143, and are typical for British psychology courses. Students' overall performance in the first year of their degree ranged from $40 \%$ (since this is the minimum required to progress to the second year of study) to $78 \%$ with a mean of $58 \%$ (SD $=6.81$ ).

\section{Measurement of study orientation}

Students' study orientations were measured using the 18 item Approaches to Studying Inventory (Entwistle and Ramsden, 1983). This inventory measures students' motivation and cognitive approaches to studying on three scales: achieving orientation, reproducing orientation, and meaning orientation. These scales are described in Table 1. Students' total scores on these scales are discussed in the results section.

Insert Table 1 about here

\section{Teaching unit and online environment}

At the University of Portsmouth (UK), Biological Psychology is taught in the second year of a 3-year undergraduate Psychology degree. Class contact consists of 24 onehour lectures and two practical classes of three hours each, over a period of 12 weeks. Students' performance on this course was assessed by two practical reports and a 1.5hour exam. The exam is composed of 35 multiple-choice questions (to assess knowledge of the basic principles and the nervous system), one brain figure to be labelled (to assess knowledge of brain anatomy), and a choice of two out of five essay questions (to assess deeper understanding of the biological bases of two types of behaviour). 
To supplement the lectures and practical classes, an online learning environment was made available to the students (password protected). This environment was designed using WebCT (version 3.6), which is a widely used software programme that provides a variety of educational tools to facilitate learning and communication. In addition, WebCT enables each student's use of this environment to be monitored and recorded, in terms of access and participation. Access, use and several of the special features of WebCT were demonstrated in the first Biological Psychology lecture, supported by a handout. In lectures thereafter students were repeatedly encouraged to visit the online learning environment by pointing out the information and exercises available, by referring to discussion topics, and by incorporating some of the issues brought forward by the students into the lectures. A variety of learning support was available on the course Web site: (i) information regarding course content and organisation (e.g., learning objectives, study tasks, references to additional literature and relevant Websites), (ii) practical learning via a self-assessment quiz, and (iii) an opportunity for dialogue via a bulletin board. No extrinsic reward was given for using this resource.

\section{Measures of online learning}

General Web use was measured by the number of times the Biological Psychology homepage was accessed (Hits) and the overall period of access (Period of access in weeks). The use of the Web for dialogue was measured by the number of items read (Items read) and posted (Items posted) on a bulletin/discussion board. The extent to which students utilised the Web for self assessment was measured by students' performance on an online self-assessment quiz (Quiz performance) and the number of 
times this quiz was attempted (Quiz attempts). The self-assessment quiz provided feedback to the individual student after electronic submission of his/her answers to all 35 multiple-choice questions. There was a set time limit of 30 minutes and performance data were available to the instructor. In an attempt to stimulate early revision students were asked to access the Web site by the middle of the teaching semester $\left(6^{\text {th }}\right.$ teaching week). They were told that if they failed to do so, they would not be given subsequent access to the quiz element of this site.

\section{Results}

\section{Study orientation}

The mean scores on the achievement, reproduction, and meaning orientation were 15.5 $(\mathrm{SD}=2.8), 13.8(\mathrm{SD}=2.9)$, and $16.5(\mathrm{SD}=3.1)$ respectively. The data approached a normal distribution on all three learning orientations. Females were found to score slightly higher on the reproductive orientation $(M=13.9)$ than males $(M=12.6, t=2.10$, $\mathrm{df}=25.7, \mathrm{p}<.05$ ), while there were no significant gender differences for the other two learning orientations. Age was found to correlate with meaning orientation $(\mathrm{r}=0.234$, $\mathrm{p}<.05$ ) indicating that with age students appeared to have developed a deeper approach of studying and a higher intrinsic motivation. This was confirmed by a t-test comparing young students ( $\leq 21$ years, $M=16.3$ ) with older students ( $>21$ years, $M=18.9, t=2.56$, $\mathrm{df}=108, \mathrm{p}<.05$ ). Older students also tended to score slightly higher on achievement orientation $(\mathrm{M}=17.0)$ than younger students $(\mathrm{M}=15.4, \mathrm{t}=1.68, \mathrm{df}=103, \mathrm{p}=0.095)$. There was no age difference for reproductive orientation.

\section{Web use}


A summary of how students used the Biological Psychology Web-site is given in Table 2. Many students seem to have used the Web-site extensively, however a big variety in use was noted as well. For example, while the mean number of Hits (86.3) could be considered to be high, a standard deviation of 87.6 and a range of 1 to 310 referred to a large variability in the number of visits. Similarly, students accessed the Web site over a period of almost 10 weeks on average, but some students visited it only once (period of access $=0, N=8$ ) while others visited it over the whole semester period (period of access $>12, \mathrm{~N}=32$ ). Furthermore, it should be noted that a respectable mean number of Items read (59.5) contrasted sharply with the mean number of Items posted (0.8).

Insert Table 2 about here

As a first indication of whether Gender or Age may influence Web-use, it was found that a larger proportion of males seem to have used the Web site for dialogue (24\%), compared to only $15 \%$ of females. In terms of self-assessment, males and females were comparable, with $59 \%$ of males making 2 or more attempts at the quiz, compared to $51 \%$ of females. $50 \%$ of those aged 21 or under attempted the quiz on 2 or more occasions, compared to $70 \%$ of those aged over 21 . A greater proportion of females accessed the Website early (61\%) (before week 6) than males (47\%).

\section{Can we predict students' use of this virtual learning environment?}

A series of multiple regression analyses (stepwise) were carried out, each with the following predictor variables: age, gender, academic ability, total meaning orientation 
score, total reproducing orientation score and total achieving orientation score. In addition a series of discriminant function analysis (stepwise) were carried out, with age, ability, total meaning orientation score, total reproducing orientation score and total achieving orientation score entered as independent variables. The dependent variables used are described in Table 3, with continuous variables being used in the multiple regression analysis and a recoded version of these variables used in the discriminant function analysis.

------- Insert Table 3 about here -----

\section{Overall WebCT Use}

A multiple regression revealed that the number of homepage visits (hits) a student made was best predicted by a model including only Age (Adjusted R Square $=.141 ; 1,101=$ 17.721, $P<0.005$ ) with the number of hits increasing as age increases (Beta .386, $P<$

0.005). A further multiple regression revealed that the model best predicting the period of students' use of WebCT again incorporated only their Age (Adjusted R Square = $\left..039 ; F_{1,101}=5.14, P<0.05\right)$. In this case too, as age increased so did length of access (Beta .220, $P<0.05)$.

\section{Dialogue}

A multiple regression indicated that the number of items read on the bulletin board was predicted by Age (Adjusted R Square $=.109 ; F_{1,101}=13.47, P<0.005$ ). As age increased so did the number of items read (Beta .343, $P<0.05$ ). In addition, a multiple regression produced a model predicting the number of messages posted on the bulletin board which again incorporated only students’ Age as a predictor (Adjusted R Square = 
$\left..166 ; F_{1,101}=21.34, P<0.005\right)$. As age increased so did the number of messages posted (Beta .418, $P<0.005)$.

A further variable was created using the 'items read' and 'items posted' scores. Students were separated into three groups, those that were inactive in dialogue (neither read nor posted messages, 23\%), those that were passive (read messages only, 60\%), and those that were active in dialogue (read and posted messages, 16\%). In a discriminant function analysis examining bulletin board use seven cases were dropped because of missing data, and a further case was dropped because it was identified as multivariate outlier. One discriminant function predicted membership of these groups (but only at the $10 \%$ significance level), with $\chi^{2}(10)=16.56, P<.10$. This discriminant function accounted for $90 \%$ of the between group variability. This function is contributed to positively by participants’ Age, Ability and Achievement orientation. Functions at group centroids indicate that this function maximally separates between active bulletin board users and the other two groups. Active bulletin board users had higher grades in the previous academic year (mean=60.56, $\mathrm{SD}=7.26$ ) than passive users (mean= 57.72, $\mathrm{SD}=6.844)$ or non-users $($ mean $=56.02, \mathrm{SD}=6.14)$. Active bulletin board users also had higher achievement orientations (mean= 16.39, SD $=3.05)$ than passive users $($ mean $=15.46, \mathrm{SD}=3.01)$ or non-users $($ mean $=14.92, \mathrm{SD}=$ 2.15). Active bulletin board users were older (mean $=23.17, \mathrm{SD}=6.90)$ than passive users $($ mean $=19.95, \mathrm{SD}=2.75)$ or non-users $($ mean $=19.42, \mathrm{SD}=0.65)$. Classification results indicate that non-users are the most accurately classified, with $63 \%$ of the cases correct. Passive users are next, with $49 \%$ being correctly classified and for active users, $39 \%$ are correctly classified. 


\section{$\underline{\text { Self Assessment }}$}

The extent to which students used WebCT to self-assess was measured by the number of attempts they made at the self-assessment quiz. Multiple regression revealed no significant model (at the 5\% level) to predict the number of attempts that students made at the quiz. Whether students made no or one attempt (48\%), or more than one attempt (52\%) at the quiz was also examined. However, no variables qualified for the discriminant function analysis.

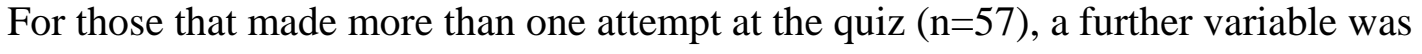
examined, whether students' mark improved (68\%), or deteriorated (32\%) (no participant's mark stayed the same) from first and final quiz attempts. In a discriminant function analysis no cases were dropped because of missing data, and one case was dropped because it was identified as multivariate outlier. One discriminant function predicted membership of these groups, with $\chi^{2}(1)=5.77, P<.05$. This discriminant function accounted for $100 \%$ of the between group variability. This function is contributed to by participants' achievement orientation. Those improving their mark had lower achievement orientations (mean= 14.81, $\mathrm{SD}=2.75$ ) than those whose marks deteriorate (mean= 16.82, $\mathrm{SD}=2.81$ ). Classification results indicated that those for whom marks deteriorated were the most accurately classified, with $71 \%$ of the cases correct. Those for whom marks improved were correctly classified in 54\% of cases.

\section{Does use of this online learning environment influence students' achievement?}


A univariate analysis of covariance was carried out with overall Biological Psychology grade as the dependent variable. The following categorical variables relating to students WebCT use (see Table 3) were entered as independent variables: number of hits, period of access, bulletin board use, and quiz attempts. Student variables (see Table 4) were entered as covariates. The analysis of covariance revealed no main effects.

------ Insert Table 4 about here ------

The overall unit grade was made up of exam performance (35 MC questions, brain labeling, essay questions) and coursework performance (2 practical reports). Each of these parts was examined separately in a series of univariate analyses of covariance. Again the student variables (in Table 4) were entered as the covariates and number of hits, period of access, bulletin board use and quiz attempts were entered as dependent variables. These analyses of covariance revealed no main effects of any online learning variables for the overall coursework mark, or for either of the practical reports contributing toward this mark. Neither were there any main effects for the multiplechoice element or the brain labelling element of the examination. However, in exploring the overall examination mark there was a main effect of bulletin board use on achievement $(\mathrm{F}(2,68)=3.51, P<.05)$. As shown in Figure 1 , passive use of the bulletin board did lead to a lower mark (53\%, Lower Second) than non-use (59\%, Lower Second), but with active use leading to the highest mark (61\%, Upper Second). Employing the LSD post-hoc test, significant differences were found only between passive an active users' achievement $(P<.05)$.

-------- Insert Figures 1 and 2 about here ------ 
Analysis of covariance looking at the essay component of the examination also revealed a main effect of bulletin board use on achievement $(\mathrm{F}(2,68)=4.34, P<.05)$. As shown in Figure 2, passive use of the bulletin board was associated with a lower mark (45\%, Third Class). There was no difference between non-use (53\%, Lower Second) and active use (53\%, Lower Second). Employing the LSD post-hoc test, significant differences were found between passive an active users achievement $(P<.05)$ and passive and non-users $(P<.05)$.

\section{Discussion}

Providing opportunities to practice a broad range of generic skills, interact with an engaging and authentic environment, make sense of experiences, obtain more feedback, enhance computer literacy and therefore career development are just some of the potential advantages for students that engage in online learning environments, discussed in the introduction (see Krantz \& Eagley, 1996; Oliver \& McLoughlin, 2001; Hammond \& Trapp, 2001; Collis, De-Boer \& Slotman, 2001; Heinssen, Glass and Knight, 1987; Miura, 1987). However, the assumption has often been that offering Web-based learning environments leads to Web-based learning. In fact little was known about which students utilised these resources, or the impact of their use on academic achievement. The current research has highlighted that not all students are likely to utilise the opportunities offered by online course support and hence cannot realise these pedagogic advantages.

\section{Gender}


Gender proved to be one factor in determining students’ use of Web-based learning, since a larger proportion of males than females entered into dialogue with their peers and teachers (via the use of a bulletin board). It appears that the males examined here are not encountering the problems identified by Arbaugh (2000) and Jackson, Ervin, Gardner and Schmitt (2001), who found that male students were less inclined to engage in Web dialogue. Furthermore, Chmielewski's (1998) finding regarding more frequent use of the Web by men was not supported. In this instance gender predicted neither the number of home page hits, nor the period of access to the Web site. While it is important to note the gender imbalance in the current cohort, there is another key difference between the previous findings and those in the current study. That is that the former were based on self-report and the latter relies on data of actual Web use. It is not unreasonable to suggest that reported Web use does not necessarily correspond to actual behaviour.

\section{Age}

While any finding related to age suggested by the current data must be carefully considered given the small cohort of mature students, it seems that age plays a significant role in determining students' use of online learning. General Web use (number of homepage hits, and period of access) increased with age, as did use of the bulletin board to engage in dialogue. These findings refute those of Morrell, Mayhorn \& Bennett (2000) who reported that older adults were less inclined to use the Web. However, their mature population was aged over 75, significantly older than those in the current study. The current authors are inclined to think that the difference between these findings reflects the nature rather than the age of the participants. For example, 
the older adults investigated here have higher levels of education than in previous studies, excellent access to computers and IT training commensurate with their younger counterparts (provided in the first year of their degree). These are all factors with a track record for influencing Web use (see Chmielewski, 1998; Morrell, Mayhorn \& Bennett, 2000). Furthermore, the current population have an incentive for using the Web (the potential for improving academic performance) not applicable to the domestic user.

Since the older adults in the current study demonstrated higher meaning orientation scores, represented by an interest in learning for learning's sake (see also Harper \& Kember, 1986; Richardson, 1994, 1997) one might expect this to adequately explain their sophisticated use of WebCT. This is particularly feasible given the reaccuring theme in existing literature indicating that the use of information technology depends on motivation (Tolmie \& Anderson, 1989; Martinez, 1999; McManus, 2000). However, the current data indicates that it is achieving orientation, not meaning orientation that is associated with WebCT use. Hence, when older adults are not disadvantaged by lack of general education, IT knowledge and access to computers they are more active in their use of online learning than younger adults, but it is difficult to ascertain why this may be the case. The only explanation suggested by the current study and others is that the superior academic ability of mature students (see also Newstead, Hoskins, FranklynStokes \& Dennis, 1997) might explain their increased use of WebCT. Certainly, the greater the student's ability the more likely they were to enter into dialogue via the bulletin board. 


\section{Approaches to Studying and Ability}

The current data revealed that active bulletin board users were those with superior ability and higher achievement orientation scores than passive or non-users. The dual effect of these variables was not due to any relationship between achievement orientation and ability (as indicated by achievement in the previous academic year). Although one might expect these variables to be related, further investigation revealed no significant correlation between them $(-.03, P>.05)$. Hence we must explore the impact of ability and achievement orientation on bulletin board use independently.

In order to discuss the relationship between bulletin board use and achieving orientation we should first recap. Achieving orientation measures the extent to which a student is strategic, organised, aware of academic demands and works effectively to facilitate high academic achievement. This suggests several reasons why high achieving orientation scores might relate to bulletin board use. Being organised must surely allow a student the luxury of spending time on online learning activities. Even though WebCT use was not rewarded or assessed, a strategic student might be inclined to use any tool, which might facilitate their achievement. Furthermore, maintaining an awareness of academic demands is likely to increase a student's inclination to enter into dialogue with peers and lecturers via any means (see Miller \& Parlett, 1974) the bulletin board being just one.

A possible explanation for the relationship between ability and bulletin board use might be found in constructivism. Vygotsky (1978) states that learning is intrinsically social where exposing yourself to others' thinking processes promotes cognitive growth. In 
essence we learn to think by incorporating what we hear from others. Based on this perspective one might assume that able learners are likely to engage in sophisticated learning strategies that entail seeking multiple perspectives via dialogue with other learners. Miller and Parlett (1974) found that 'cue seekers', that is students actively seeking communication with lecturers and peers achieved the highest degree classifications. This might explain why in the current study active bulletin board use was associated with increased overall academic achievement.

In addition, active bulletin board use was related to higher performance in the essay element of the assessment. Essay writing is a complex assessment task which requires a wide range of skills such as the selection, integration, organisation, evaluation and creative use of material (Henderson, 1980). Again, returning to constructivism, it is this part of the course assessment that is most likely to have required a sophisticated level of cognitive functioning. Many have argued that this level of processing cannot be taught, but can be developed through active learning (Bransford, Sherwood, Vye and Rieser, 1986). Nevertheless many writers have focused their attention on producing research or support material aimed at enhancing these skills, particularly in writing (Entwistle, 1995; Hall, 1989; Wason, 1985). Hence it is extremely promising that entering into dialogue, via Web-based course support, which is neither staff nor time intensive, can influence achievement in writing, and can perhaps even facilitate cognitive growth.

Constructivism might also explain why passive users of the bulletin board achieved lower marks than non-users. Perhaps seeking others’ perspectives without actively engaging in social learning (which assists the learner making sense of these 
perspectives) may prove confusing and therefore detrimental to cognitive growth. It seems then that a potentially powerful learning tool exists in bulletin boards and other methods of online learning which provide opportunities for, and stimulate dialogue, if students can be encouraged to use them actively.

However, one anomaly remains. The current data suggests that students with lower achieving orientation scores (those that are less strategic and organised) were more likely to improve their mark from first to last attempt at the online quiz. This indicates that a strategic approach to studying applied with some aspects of online learning, namely self-assessment, is not beneficial. This adds credence to and elaborates on the idea that learning which utilises IT (beyond human computer interaction scenarios) may not be appropriate for all learners (see Enochs et al., 1985; Wood et al., 1996; Ross \& Schulz, 1999).

\section{Conclusion}

The finding that dialogue, via an online learning environment, can influence achievement is extremely promising. However, it must be noted that when an opportunity for dialogue is offered individual differences will determine the extent to which students utilise this. The tendency for this resource to engage already highly motivated and academically able students is worrying. However, the finding that gender and age play a role in the degree of activity on bulletin boards, which cannot be accounted for by motivation, although they may be accounted for in part by ability, provides an indicator that beneficial aspects of online learning could have a wider appeal. However, realising this appeal will require in depth analysis of student cohorts 
which does not overlook their diversity. In the first instance more research is required to confirm or refute these findings, specifically that which incorporates a larger population of mature students and which manipulates whether or not the use of an online learning environment is assessed. Future research might also benefit from separate and more detailed investigation of a variety of potential ingredients for Webbased learning environments. This could result in a greater understanding of the relationship between specific aspects of online environments and achievement, as well as identifying which resources engage specific sub-sections of the student population. Furthermore it would be beneficial to know whether students that enter online learning environments to use particular resources will generalise their use to other pedagogically useful aspects of that learning environment. In conclusion, any future research should focus on developing online learning environments that include content and styles of delivery that promote learning while also engaging a wide student population. 


\section{References}

Arbaugh, J. B. (2000) An exploratory study of the effects of gender on student learning and class participation in an Internet-based MBA course. Management Learning. 31(4) 503-519.

Bransford, J. D., Sherwood, R., Vye, N. J. and Rieser, J. (1986). Teaching thinking and problem solving: Research foundations. American Psychologist, 41, 1078-1089.

Chmielewski, M. A. (1998) Computer anxiety and learner characteristics: Their role in the participation and transfer of Internet training. Dissertation Abstracts International Section A: Humanities and Social Sciences. 59.

Collis, B., De-Boer, W. and Slotman, K. (2001) Feedback for Web-based assignments. Journal-of-Computer-Assisted-Learning. 17(3) 306-313.

Enochs, J. R., Handley, H. M. and Wollenberg, J. P. (1984) The relationship of learning style, reading volcabulalry, reading comprehension and aptitude for learning to achievement in the self-paced computer-assisted instructional modes of the yeoman "A" school at the Navel Technical Training Centre, Meridian. Paper presented at the annual meeting of the Mid-South ERA, New Orleans.

Entwistle, N. J. (1995). Frameworks for Understanding as Experienced in Essay writing and in preparing for examinations. Educational Psychologist, 30 (1), 47-54.

Entwistle, N. J., and Ramsden, P. (1983). Understanding Student Learning. Australia: Croom Helm Ltd.

Hall, J. (1989). Essays and Exams: A Practical Approach for Students. Cambridge: University of Cambridge Local Examinations Syndicate.

Hammond, N. V. and Trapp, A. L. (2001). How can the web support the learning of Psychology? In C. R. Wolfe (ed.), Learning and Teaching on the World Wide Web. Academic Press: New York, pp 153-169

Harper, G. and Kember, D. (1986). Approaches to study of distance education students. British Journal of Educational Technology, 17, 212-222.

Hayes, K. and Richardson, J. T. E. (1995) Gender, subject and context as determinants of approaches to studying in higher education. Studies in Higher Education. 20 (2) 215-221.

Heinssen, R. K., Glass, C. R. and Knight, L. A. (1987). Assessing computer anxiety: development and validation of the Computer Anxiety rating Scale. Computers in Human Behaviour, 3, 49-59.

Henderson, E. S. (1980). The Essay in Continuous Assessment. Studies in Higher Education, 5 (2), 197-203.

Hoskins, S. L., Newstead, S. E. and Dennis, I. (1997) Degree Performance as a function of age, sex, prior qualifications and discipline studied. Assessment and Evaluation in Higher Education, 22 (3).

Howe, C. (1998) Psychology teaching in the $21^{\text {st }}$ Century. The Psychologist, 11 (8), 371-373

Jackson, L. A., Ervin, K. S., Gardner, P. D. and Schmitt, N. (2001) Gender and the Internet: Women communicating and men searching. Sex-Roles. Vol 44(5-6). pp. 363-379.

Jiang, M. and Ting, E. (2000). A study of factors influencing students' perceived learning in a Web-based course environment. International Journal of Educational Telecommunications. 6 (4) 317-338.

Krantz, J. H. and Eagly, B. M. (1996). Creating psychological tutorials on the WorldWide Web. Behavior Research Methods, Instruments, and Computers, 28, 156-160. 
Martinez, M. A. (1999) An investigation into successful learning: Measuring the impact of learning orientation, a primary learner-difference variable, on learning. Dissertation Abstracts International Section A: Humanities and Social Sciences. 60.

Maye, T. (1998) Teaching, technology and talk. The Psychologist, 11(8) 375-377.

McManus, T. F. (2000). Individualizing instruction in a Web-based hypermedia learning environment: Nonlinearity, advance organizers, and self-regulated learners. Journal of Interactive Learning Research. 11(2). 219-251.

Miller, C. M. L. and Parlett, M. (1974) Up to the mark: A study of the Examination Game, London: S.R.H.E.

Miura, I. T. (1987). The Relationship of Computer Self Efficacy Expectations to Computer Interest and Course Enrolment in College. Sex Roles, 16, 303-311.

Morrell, R. W., Mayhorn, C. B. and Bennett, J. (2000). A survey of World Wide Web use in middle-aged and older adults. Human Factors. 42 (2) 175-182.

Musgrove, A. T., Knee, R., Rodney, D.W. and Musgrove, G. (2001). Using WebCT 3 to create Web-based learning for multiple learning styles. Technology and Teacher Education Annual, 2, 1455-1459.

Newstead, S. E., Hoskins, S. L., Franklyn-Stokes, A. and Dennis, I. (1997) Older but Wiser? Mature students in higher education, in P. Sutherland (Ed.) Adult Learning: A reader. London: Kogan Page

Oliver, R. and McLoughlin, C. (2001) Exploring the practise and development of generic skills through Web-based learning. Journal of Educational Multimedia and Hypermedia. 10 (3). 207-225.

Owston, R. D. (2000) Evaluating Web-based learning environments: Strategies and insights. CyberPsychology and Behavior. 3 (1) 79-87.

Plous, S. (2000). Tips on Creating and Maintaining an Educational World Wide Web Site. Teaching of Psychology, 27, 63-70.

Richardson, J. T. E. (1994). Mature students in higher education: 1. A literature survey on approaches to studying. Studies in Higher Education, 19, 309-325.

Richardson, J. T. E. (1997). Dispelling some myths about mature students in higher education: Study skills, approaches to studying and intellectual ability. In P. Sutherland (Ed.), Adult Learning: A Reader. London: Kogan Page.

Rogers, C. G., Galloway, D., Armstrong, D. and Leo, E. (1998) Gender differences in motivational style: a comparison of measures and curriculum area. British Journal of Educational Psychology, 68, 189-202.

Ross, J. L. (2000) An exploratory analysis of post-secondary student achievement comparing a Web-based and a conventional course learning environment. Dissertation-Abstracts International Section A: Humanities and Social Sciences. 61.

Ross, J. and Schulz, R. (1999) Can computer-aided instruction accommodate all learners equally? British Journal of Educational Technology, 33 (1) 5-24.

Sherman, R. C. (1998). Using the World Wide Web to teach everyday applications of social psychology. Teaching of Psychology, Entwistle, N. J., and Ramsden, P. (1983). Understanding Student Learning. Australia: Croom Helm Ltd., 212-216.

Tolmie, A. and Anderson, T. (1989) Information technology and peer-based tutorials. The Psychologist. 11 (8), 381-384

Wason, P. C. (1985). How to write an essay. The New Psychologist, May, 16-19.

Vygotsky, L. S. (1978) Mind in the society: The development of higher psychological processes. Cambridge, MA: Harvard University Press. 
Ward, M. and Newlands, D. (1998) Use of the Web in undergraduate teaching. Computers and Education, 31, 171-184.

Wood, F., Ford, N., Miller, D., Sobczyk, G. and Duffin, R. (1996) Information skills searching behaviour and cognitive styles for student-centred learning: a computer assisted learning approach. Journal of Information Sciences 22 (2) 79-92. 
Table 1: The three scales of the Approaches to Studying Inventory as summarised by Entwistle and Ramsden (1983)

\section{Scale}

Meaning orientation

Deep approach

Intrinsic motivation

Reproducing orientation

Surface approach

Syllabus-boundness

Extrinsic motivation

\section{Meaning}

Active questioning in learning.

Interest in learning for learning’s sake.

Preoccupation with memorising.

Relying on staff to define learning tasks.

Interest in course for the qualifications they offer.

Achieving orientation

Strategic approach

Organised study methods

Achievement motivation
Awareness of implications of academic demands. Able to work regularly and effectively.

Competitive and competent. 
Table 2: Summary of students' Web use

Mean SD Range

\section{General Web use}

$\begin{array}{lccc}\text { Hits } & 86.3 & 87.6 & 1-310 \\ \text { First access (in weeks) } & 3.6 & 1.7 & 1-8 \\ \text { Period of access (in weeks) } & 9.9 & 4.2 & 0-16\end{array}$

\section{Practical Learning}

$\begin{array}{lccc}\text { Quiz performance }(\max 35) & 18.1 & 7.9 & 0-34 \\ \text { Quiz attempts } & 2.2 & 1.8 & 0-8\end{array}$

Quiz attempts

2.2

$0-8$

\section{Dialogue}

Items read

59.5

71.2

$0-219$

Items posted

0.8

2.7

$0-19$ 
Table 3: Continuous and Categorical Dependent Variables used to Measure Students Use of WebCT

\begin{tabular}{|c|c|c|c|}
\hline & Continuous Variables & Categorical Variables & $\mathbf{N}$ \\
\hline \multirow[t]{2}{*}{$\begin{array}{l}\text { Overall } \\
\text { Web Use }\end{array}$} & $\begin{array}{l}\text { Hits } \\
\text { Number of homepage visits. }\end{array}$ & $\begin{array}{l}\text { Frequency of Hits } \\
1-10 \\
11-50 \\
51-150 \\
\text { more than } 150\end{array}$ & $\begin{array}{l}26 \\
25 \\
31 \\
28\end{array}$ \\
\hline & $\begin{array}{l}\text { Period of Access } \\
\text { Number of weeks from first to last access. }\end{array}$ & $\begin{array}{l}\text { Timing of Access } \\
\text { Before week } 6 \text {. } \\
\text { After week } 6 .\end{array}$ & $\begin{array}{l}65 \\
45\end{array}$ \\
\hline \multirow[t]{2}{*}{ Dialogue } & $\begin{array}{l}\text { Read } \\
\text { Number of messages read on the bulletin board. }\end{array}$ & $\begin{array}{l}\text { Bulletin Board Use } \\
\text { Inactive. } \\
\text { Passive users (read messages). } \\
\text { Active users (read and posted messages). }\end{array}$ & $\begin{array}{l}26 \\
66 \\
18\end{array}$ \\
\hline & $\begin{array}{l}\text { Posted } \\
\text { Number of messages posted on the bulletin } \\
\text { board. }\end{array}$ & & \\
\hline \multirow[t]{2}{*}{$\begin{array}{l}\text { Practical } \\
\text { Learning }\end{array}$} & $\begin{array}{l}\text { Quiz Use } \\
\text { Number of attempts at quiz. }\end{array}$ & $\begin{array}{l}\text { Quiz Attempts } \\
1 \text { attempt } \\
\text { more than } 1 \text { attempt. }\end{array}$ & $\begin{array}{l}53 \\
57\end{array}$ \\
\hline & $\begin{array}{l}\text { Effort } \\
\text { Length of time (in minutes) of first attempt). }\end{array}$ & $\begin{array}{l}\text { Development } \\
\text { For those that make more than } 1 \text { attempt }(\mathrm{n}=57) \text { : } \\
\text { Final mark improved. } \\
\text { Final mark deteriorated. }\end{array}$ & $\begin{array}{r} \\
39 \\
18\end{array}$ \\
\hline
\end{tabular}


Table 4: Variables and Levels Measuring Individual Differences in Students

\begin{tabular}{|c|c|c|}
\hline Variable & Groups & $\mathbf{N}$ \\
\hline Achieving Orientation & $\begin{array}{l}\text { High } \\
\text { Average (equal to, } 1 \text { less than and 1more than median) } \\
\text { Low }\end{array}$ & $\begin{array}{l}21 \\
45 \\
38\end{array}$ \\
\hline Reproducing Orientation & $\begin{array}{l}\text { High } \\
\text { Average (equal to, } 1 \text { less than and 1more than median) } \\
\text { Low }\end{array}$ & $\begin{array}{l}26 \\
44 \\
34\end{array}$ \\
\hline Meaning Orientation & $\begin{array}{l}\text { High } \\
\text { Average (equal to, } 1 \text { less than and 1more than median) } \\
\text { Low }\end{array}$ & $\begin{array}{l}34 \\
45 \\
25\end{array}$ \\
\hline Ability & $\begin{array}{l}\text { More than 69\% } \\
\text { More than 59\% } \\
\text { More than 49\% } \\
\text { More than 39\% }\end{array}$ & $\begin{array}{l}5 \\
38 \\
57 \\
9\end{array}$ \\
\hline Age & $\begin{array}{l}21 \text { or under } \\
\text { Over } 21\end{array}$ & $\begin{array}{l}100 \\
10\end{array}$ \\
\hline Gender & $\begin{array}{l}\text { Male } \\
\text { Female }\end{array}$ & $\begin{array}{l}17 \\
93\end{array}$ \\
\hline
\end{tabular}


Figure 1: Estimated Marginal Means of Biological Psychology Examination Marks by Bulletin Board Use.

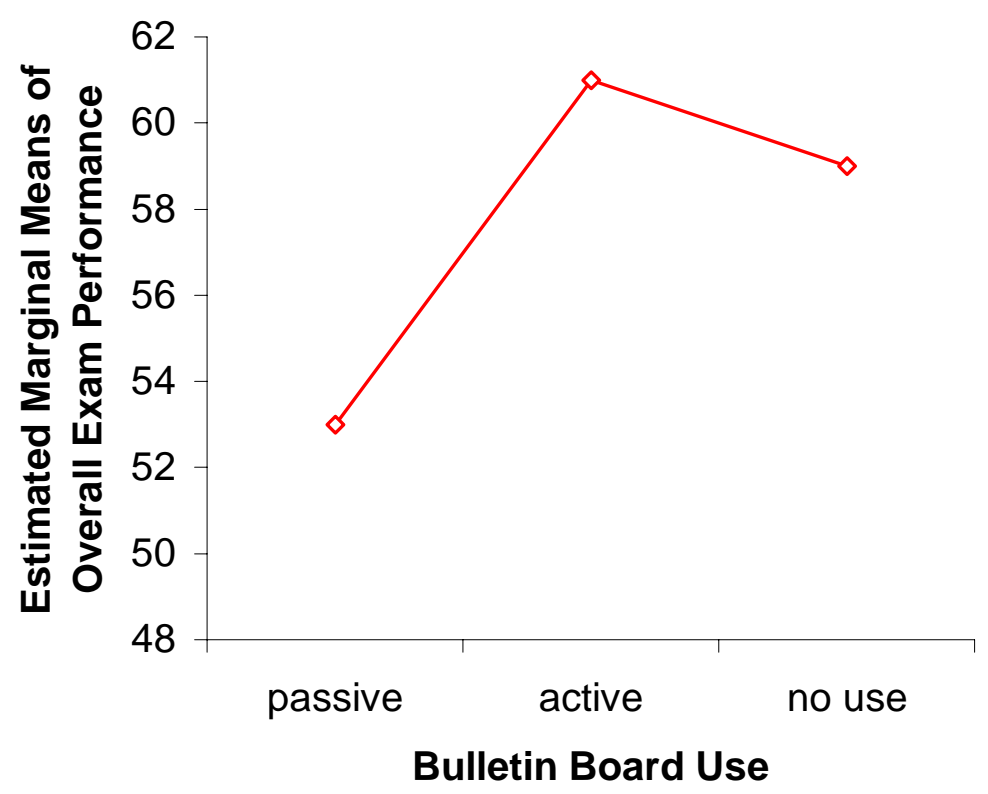


Figure 2: Estimated Marginal Means of Biological Psychology Examination Essay Marks by Bulletin Board Use.

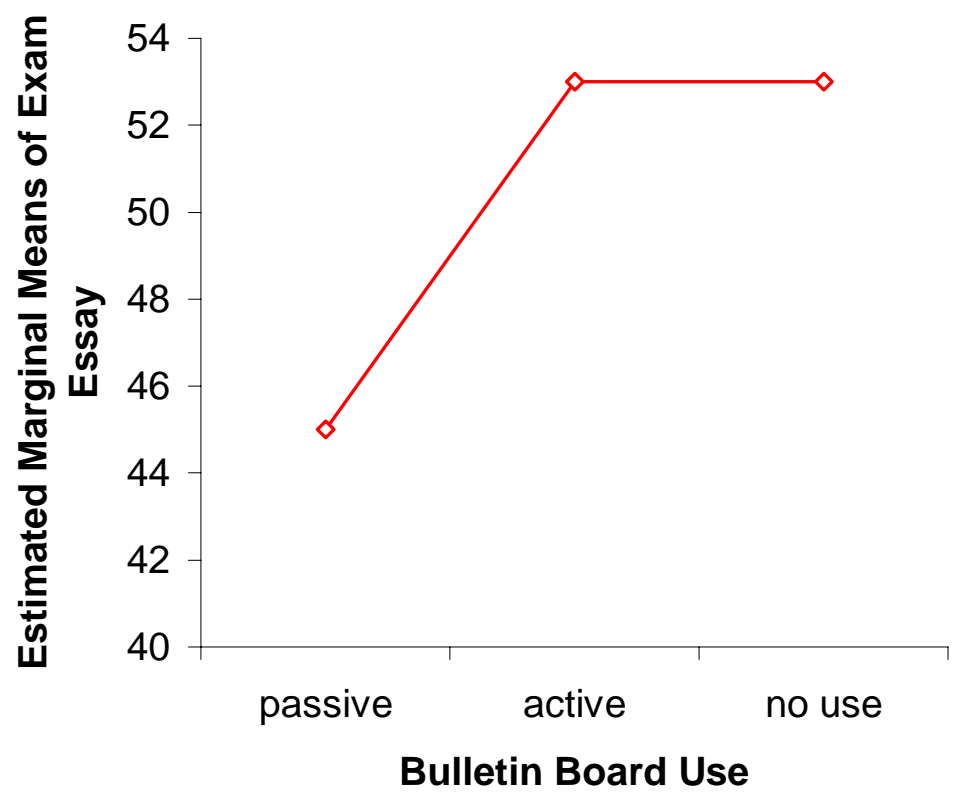

